\title{
A Literature Review on Innovation-Driven Development in China-----Based on Citespace 5.3 Knowledge Graph Analysis
}

\author{
Zhengxia Tang \\ School of Economics \\ Central University of Finance and Economics \\ Beijing, China \\ Lapo Hou \\ School of Yi Language and Culture \\ Xichang University \\ Xichang, China \\ Fengrong Liu \\ Center for China Fiscal Development \\ Central University of Finance and Economics \\ Beijing, China
}

\begin{abstract}
Innovation-driven development is one of the most important strategies in many countries and thus related study on it matters. After searching research papers with the topic of innovation-driven development (1998 to 2018) from Chinese Social Sciences Citation Index, we generate knowledge graphs produced by Citespace5.3 to conclude that: (1) The connotation of innovation-driven development involves the modes of economic development and the adjustment of productive factors; (2) Occurrence frequency of innovation-driven development as a keyword becomes higher since 2008; (3) The study on innovation-driven development in China mainly includes the reasons, explanations and measures.
\end{abstract}

Keywords: innovation-driven development, connotation, hot topics, Citespace5.3

\section{Introduction}

International competition is getting more and more fierce under the background of globalization, as a result, the capacity of innovation has become a new drive to the development strategy. Confronted with financial crisis or resource constraint, many countries have set innovation as national guidelines. National Medium and Long-term Science and Technology Development Program put up by China, National Innovation Strategy by the U.S as well as strategies by Japan, Europe Union, etc., all involve innovation-driven development (Yuan, 2014).

China has become the second largest economy in the world since it exceeded Japan in 2010. However, enterprises in China are now facing tough challenges of the environment contamination problems caused by industrialization, diminishing demographic dividends, complicated international background (Suo, 2014). 18th National Congress of the Communist Party of China emphasized innovation as the principal development concept and innovationdriven development as the way to get rid of middle-income trap.Pursuing innovation development and strengthening the quality and benefits of development is the first goal in Recommendations for the 13th Five-Year Plan for Economic and Social Development (Liu, 2016).

Theories, experiences and policy studies on innovation-driven development is thus of vital importance. Research topics are along upgraded as the implementation of new national strategies. Based on literature searching result of China Knowledge Resource Integrated Database (CNKI), papers on innovation-driven development emerged and increase from 2008. This paper analyzes innovation-driven development and its hot research topics in China applying knowledge graph results of the software CiteSpace5.3. 


\section{Method and Data}

\subsection{Knowledge Graph Analysis by Citespace5.3}

Evolution of scientific structure theory holds that no matter scientific research goes fast or slowly, its pattern can be identified by tracingresearch paces $(\mathrm{KuKn}, 1962)$.Professor Chen Chaomei develops the software called CiteSpace5.3 to analyze potential knowledge through visual graph showing the structure and distribution of scientific research.Analysis of networks, structures, interactions or overlaps of knowledge units or groups can further produce new knowledge (Chen, 2015).

Visualization by CiteSpace5.3 is based on the nodes and ties relationships of the whole knowledge structure. A node is a keyword and two keywords in the same paper generate a tie between these two nodes, therefore, further a network. The strength of correlations can be calculated by Cosine in this software, which is

$$
\operatorname{Cosin} e\left(c_{i j}, s_{i}, s_{j}\right)=\frac{c_{i j}}{\sqrt{s_{i} s_{j}}}
$$

$C_{i j}$ is the co-occurrence frequency of node $\mathrm{i}$ and node $\mathrm{j} . S_{\mathrm{i}}$ is the occurrence frequency of node $\mathrm{i}$ and $S_{j}$ is the occurrence frequency of node $\mathrm{j}$.

Degree Centrality is a simple but important way to describe the characteristics of a single node (Wang, 2012). A node can enjoy a higher degree centrality if it connects directly with more nodes. Software of visualization usually lays an object with high degree centrality in the center of the network and others with low degree centrality on the periphery. For a network matrix $A=\left(a_{i j}\right)_{N * \mathbb{N}}$, the degree centrality is

$$
\langle k\rangle=\frac{1}{n} \sum_{i=1}^{n} k_{i}=\frac{1}{n} \sum_{i=1}^{n} a_{i j}
$$

Relationship between degree centrality and the number of ties (1)in the network can be expressed as

$$
2 l=n\langle k\rangle=\sum_{i=1}^{n} a_{i j},\langle k\rangle=\frac{2 l}{n}
$$

Betweeness centrality implies the importance of a node in the network. It is created by Freeman in 1997 and connects various keywords to correlate different knowledge. It can be expressed as

$$
B C_{i}=\sum_{s \neq i \neq t} \frac{n_{s t}^{i}}{g_{s t}}
$$

Closeness centrality indicates the degree of independence, which is

$$
C C_{\mathrm{i}}=\frac{1}{d_{i}}=\frac{n}{\sum_{j=1}^{N} d_{i j}}
$$

Eigenvector centrality is an indicator that tells the importance of the node in the whole, which is

$$
T C_{i}=\frac{1}{\lambda} \sum_{i \in A} a_{i, j} x_{i}
$$

Nodes in the network are marked i, j,s and t. Real tie quantity is 1 , and $n$ is the number of the nodes. is the number of shortest paths between node $\mathrm{s}$ and node $\mathrm{t} . n_{s t}^{i}$ is the number that shortest paths from node $\mathrm{s}$ to node $\mathrm{t}$ which pass node $\mathrm{i}$.

\subsection{Data Source}

We searched keywords include innovation-driven and innovation-driven development in Chinese Social Sciences Citation Index (CSSCI) from 1998 to 2018. Results mainly distribute after 2008. After deleting conference or news report literatures, we got 330 papers and knowledge graphs by CiteSpace5.3.

\section{Connotation of Innovation-driven Development in China}

The implementation of innovation-driven development strategy is crucial to solve problems in the economy. First of all, we summarize the key connotation of innovation-driven development based on literature review, which contains three essential aspects: First is the concept of innovation. Innovation is the engine of a prosperous country. Innovation, literally, means to create new things. 
The theory of economic development (Schumpeter,1992)by Austrian economist Joseph Alois Schumpeter first comes up with the concept of innovation and explains it as introducing new kinds of productive factor and production condition combination into production system. The concept of innovation is abundant of technology innovation, management innovation, business modes innovation, craft innovation and so on. The final goal of innovation is to attain business value (Wang, 2014). Therefore, innovation development is aneconomic mode driven by innovation.

Second is the connotation of innovation theory. Innovation-driven is proposed by Michael E.Porter. When a country enters the stage driven by innovation, a lot of industries will emerge complete "diamond systems" (Chen, 2009). Wang et al. (2014) holds thataninnovation-driven economy is mainly led by technology, R\&D, management innovation and system innovation instead of capital or cheap labor. Third is relationship between national strategy and innovation. The strategy of innovation-driven development emphasizes that economic development should be driven by innovation. The innovation drive is a new source of power to achieve the China Dream. The system structure of innovation is consist of administrative system, financial and monetary system, public finance and taxation system, ownership protection system, culture system, official staff management system and so on (Huang, Li,2016).

In conclusion, the focus of innovation-driven development is to create new knowledge, new technology, new industry, new pattern and new structures of production, applying innovation to improve the quality of economy and the structure of industries.

\section{Evolvement of study on innovation-driven development in China}

In this section, we analyze the evolvement of the study of innovation-driven development in China to look for the discipline behind it. Yu (2010) defines innovation as introducing new opinion and method into practice, creating new object to improve the current situation. Innovation-driven development is a necessity to new normal economy in China (Chen, Sun, 2016). Therefore, there are a lot researches on strategy, the path and new normal economy. Chen (2013) argues that innovation is the essential power for social development, and innovation is a capacity to create, transfer and apply knowledge into wealth. The mode of innovation-driven development not just solves the problems of efficiency, but rather to create new combinations to spread technology to production and business. Innovation-driven development as a strategy itself also experiences the process from exogenesis to endogenesis (Hong, 2013). Song et al. (2016) discuss about the relationship between innovation-driven development strategy in China and global value chain upgrade process. They believe that innovation-driven development will help China enhance its technology ability to occupy better position in the global value chain.

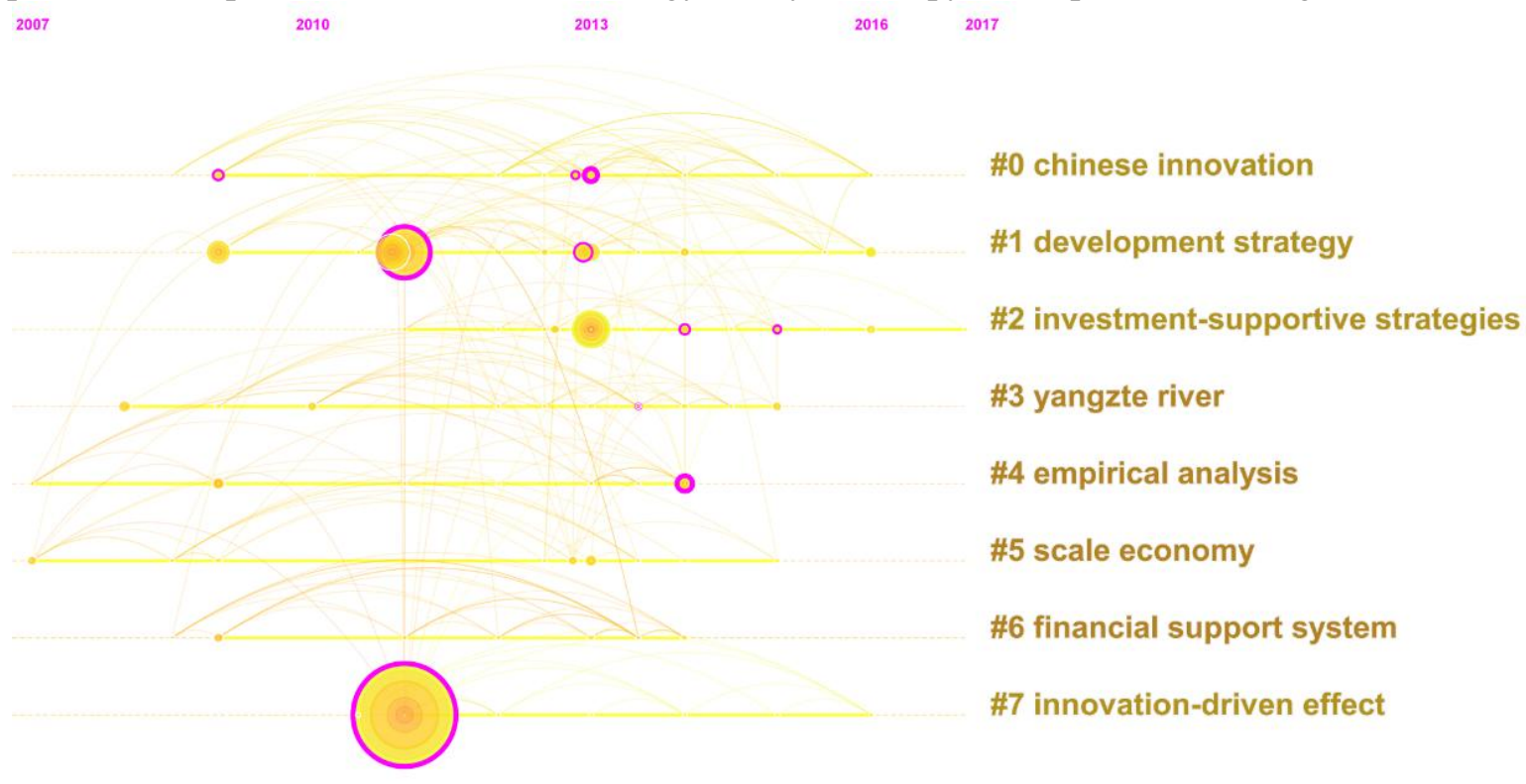

\section{Graph 1Evolvement graph of the study on innovation-driven development in China}

As we can see in Graph 1, literatures mainly appear after 2008 and keep increasing. And from 2013, the increase accelerates rapidly. Before 2008, researches are mainly about enterprise and technology innovation based on micro views. 
After the financial crisis in 2008 and a national strategy of innovation drive, the keywords change to modes of economic growth and the method of innovation-driven development. After the 18th National Congress of the Communist Party of China in 2013, the depth and width of related studies both expand sharply. There is an obvious evolvement path from enterprises, industries, regionsto the nation. In practice, New \&Hi-Tech Zone, technology zone, industrial zone are established across the country. In 2017, to establish an innovation country has becomea nationwide consensus.

\section{Hot topics of innovation-driven development in China}

In Graph 2, the location and size of the keywordsexhibit the importance and popularity of the topics in this field. We can further detect the research hot topics with the help of centrality analysis. There are several hot topics, including innovation-driven development theory, innovation-driven development strategy, innovation-driven development experiences, industrial development, scale economy, financial support, innovation-driven development path and innovation-driven development practice.

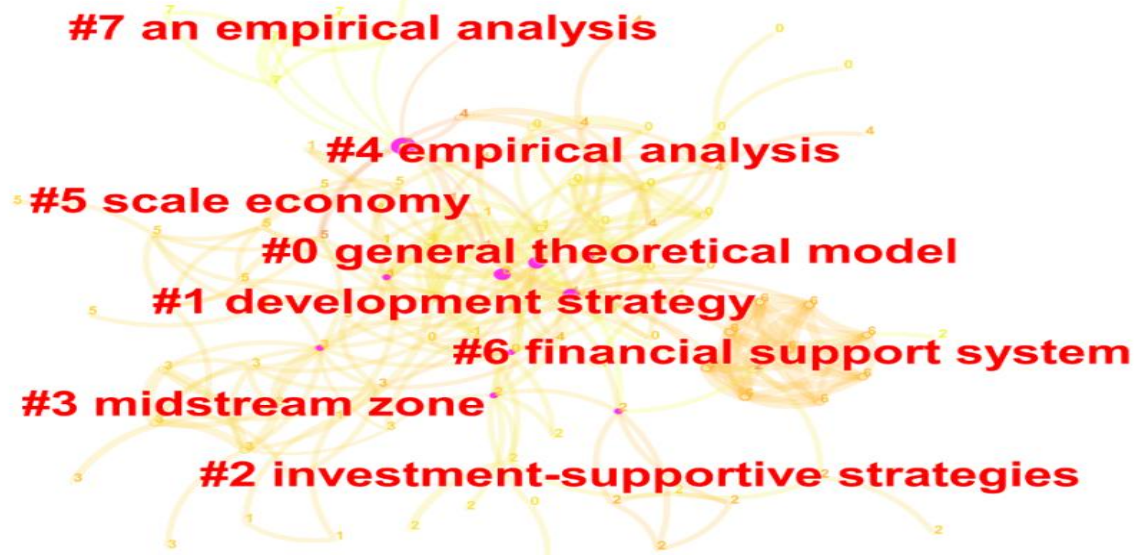

Graph 2 Keywords clustering graph of innovation-driven development First, research on innovation-driven development strategy.

The overall knowledge of innovation-driven development research in China is about national policy and strategy.Motivating innovation, encouraging initial innovation, integrating innovation resources are key points in 13th Five-year Plan (2016-2020) of China (Chen, 2015). Innovation-driven development strategy is crucial to solve contradictions and problems in the economy, and the power to support economic growth (Wang, 2013). Innovation is the key to new normal economy in China. Innovation should be the core of national development and be the leading role in the development (Cheng, 2016). Second, research on innovation drive and economic growth.

The executors of innovation are enterprises and industries. When it comes to innovation-driven development, we must notice the development of enterprises and industries. According to New Economic Geography theory, empirical results show that innovation interaction spillover, spatial increasing returns, inter-regional factor flow exerts important influence on the variety of regional innovation (Zhang, 2013). Innovation investment shows positive impact on the upgrade and improvement of industrial structure (Fu, 2013). Yan (2013) compares the impact of capital gains tax and income tax in an innovation-driven development endogenous growth model.

Third, research on innovation-driven development paths.

The path of innovation-driven development is also one of the hot topics. The systematic design of innovationdriven development calls for top-level design, products transformation, the pursuit of efficiency, the risk control and the patent protection policy (Liu, 2016). Zhang (2014) proves that there is positive correlation between competition and innovation so that competition should be encouraged to assist the R\&D activities in companies. Fourth, research on innovation-driven development practices.

The background of national policy and surroundings of regional environment is another hot theme.Different location conditions exist and good regions are more likely to attract capital, labor and companies. The innovationdriven development should suit to the local conditions and regions should create their own pattern. 
Table 1 Centrality of Keywords

\begin{tabular}{|c|c|c|c|c|c|}
\hline No. & Keywords & $\begin{array}{l}\text { Degree } \\
\text { Centrality }\end{array}$ & $\begin{array}{l}\text { Closeness } \\
\text { Centrality }\end{array}$ & $\begin{array}{l}\text { Betweenness } \\
\text { Centrality }\end{array}$ & $\begin{array}{l}\text { Eigenvector } \\
\text { Centrality }\end{array}$ \\
\hline 1 & innovation drive & 56.97 & 8.014 & 60.414 & 82.51 \\
\hline 2 & innovation-drivendevelopment & 12.727 & 7.439 & 4.881 & 14.257 \\
\hline 3 & the new normal of economy & 11.515 & 7.611 & 3.522 & 20.3 \\
\hline 4 & scientific innovation & 10.303 & 7.707 & 6.484 & 22.566 \\
\hline 5 & innovation-driven development strategy & 9.091 & 7.402 & 7.076 & 7.665 \\
\hline 6 & technology innovation & 8.485 & 7.473 & 2.766 & 14.356 \\
\hline 7 & mode of innovation-driven development & 7.879 & 7.416 & 2.889 & 12.132 \\
\hline 8 & strategic emerging industries & 7.273 & 7.6 & 0.815 & 19.051 \\
\hline 9 & economicgrowth pattern & 6.667 & 7.611 & 1.953 & 15.376 \\
\hline 10 & economic growth & 6.061 & 7.607 & 0.838 & 17.107 \\
\hline 11 & economic development & 5.455 & 7.59 & 1.406 & 14.044 \\
\hline 12 & industry upgrade & 5.455 & 7.611 & 0.899 & 16.331 \\
\hline 13 & paths & 5.455 & 7.586 & 0.63 & 16.59 \\
\hline 14 & independent innovation & 5.455 & 7.593 & 0.435 & 17.129 \\
\hline 15 & industrial structure & 4.848 & 7.545 & 0.306 & 14.278 \\
\hline 16 & innovation-driven power & 4.848 & 7.25 & 0.465 & 6.477 \\
\hline 17 & total factor productivity & 4.848 & 7.548 & 1.821 & 11.49 \\
\hline 18 & financial support & 4.848 & 7.291 & 0.585 & 4.942 \\
\hline 19 & New\&Hi-Tech Zone & 4.242 & 7.307 & 0.537 & 7.308 \\
\hline 20 & innovation city & 3.636 & 7.269 & 1.773 & 2.815 \\
\hline
\end{tabular}

\section{Conclusions}

Several conclusions are drawn from this paper: (1) Overall, the research of innovation-driven development responds to the national policy implementation; (2) According to knowledge graph and quantitative analysis, the top ten keywords are innovation drive, innovation-driven development, the new normal of economy, scientific innovation, innovation-driven development strategy, technology innovation, mode of innovation-driven development, strategic emerging industries, economic growth pattern and economic growth; (3) The evolvement of innovation-driven development study shows that the goal of innovation is more and more specific. However, researches are still in need to direct the practice and foresee the development of the country. Due to literature selections, limitations still exist and the conclusions may not be able to fully reflect all the studies. Further analysis still can be done to improve the literature review on this topic.

\section{References}

Yuan, X. H. Research on the Planning of Innovation-driven Science and Technology City[D]. Tsinghua University. 2014.

Suo, J., Li, X. J., \& Mao, J. M. The Logic and Paths of Transportation Driven by Innovation for SMEs in China[J]. Business Management Journal.2014,(09):55-66.

Liu, Y., \& Sui, S. Y. Economic Analysis of Innovation Structure and Innovation-driven[J]. Heilongjiang Social Science. 2016,(06):53-57.

Jie,L.,\&Chaomei Chen.Citespace: technology text mining and visualization[M].Beijing: capital university of economics and business press.2016,6.2-40.

Yue,C.,Chaomei,C.,Zeyuan,L.,Zhigang,H.,\&Xianwen,W.The methodology function of Cite Space mapping knowledge domains[J].Studies in Science of Science.2015,(02):242-253.DOI:10.16192/j.cnki.10032053.2015.02.009

Wang X F,Li X,Chen G R.Network science:an introduction [M].Beijing:High Education Press,2012.87-90.

Freeman L C. A set of measure of centrality based on betweenness[J].SOCIOMETRY.1997,40(1):35-41. 
Wang Changlin.Clarify Thinking Further on the Strategy of Innovation-driven Development[J].Globalization.2014,(11):29-36.DOI: 10.16845/j.cnki.ccieeqqh.2014.11.003

RongChen,T,Theory of regional innovation system theory of motivation jiaxing in zhejiang province "vice center" to build [M]. Social sciences academic press.2009,12.40-42.

Qunhui,H.,\&Xiaohua,L.,The Philosophy of Innovation: Breakthrough of Outlook on Development[J].Economic management.2016,(11):1-10.DOI: 10.19616/j.cnki.bmj.2016.11.001http://www.gov.cn/jrzg/200602/09/content_183787.htm

Kepin,Y.,Innovation: the power source of social progress[J].Marxism Reality.2000,(04):3034.DOI : 10.15894/j.cnki.cn11-3040/a.2000.04.005

Jin,C.,\&Yonglei,S., Strategic Thinking on the Innovation-driven Development[J].Science and Management.2016,(01):3-8.DOI:10.3969/j.issn.1003-8256.2016.01.001

Jin,C.,\&Gang,Z,.Innovation management: winning sustainable competitive advantage (2nd edition)[M].Beijing: Peking University press, 2013.34-35.

Yinxing,H,.On the innovation $\quad-$ driven economic development[J]. Economists,2013,(01):511.DOI: 10.16158/j.cnki.51-1312/f.2013.01.008

Jing,S.,\&Jin,C.,Implementation strategy of China's innovation-driven development strategy under the global value chain upgrade $[\mathrm{J}]$.Technical and economic,2016,(05):6-9.

Jin,C.,The Prospect of Innovation Policy in the Future Five Years[J].Science and management,2015,(01):36.DOI:10.3969/j.issn1003-8256.2015.01.001

[18]Bing,W.,The innovation, the innovation drive and driven strategy [J].Gansu Theory Research,2013,(04):24-6.

Enfu.C.,Jingsong,T.,Innovation is the primary driving force for development[J].Marxism Reality.2016,(01):1319.DOI: $10.15894 /$ j.cnki.cn11-3040/a.2016.01.003

Zhanren,Z.,Regional Difference Mechanism of innovation in china-A Case Study from the Perspective of New Economic Geography[J].Soft science,2013,(06):64-68.

Hong,F., Yunshi,M.,\&Laisheng.S.,Empirical Analysis on the Effect of Innovation on Advancement of Industrial Structure Process--Based on Panel Datas of Provinces from 2000 to 2011[J].China Industrial Economy.2013,(09):56-68.DOI: 10.19581/j.cnki.ciejournal.2013.09.006

Chengliang,Y.,\&Zhiguo,H.,Innovation Driven,Tax Distortion and Long-run Growth[J].Economic Research,2013,(12):55-67.

How does rivalry affect innovation: Evidence from china[J].China IndustrialEconomy,2014,(11):5668.DOI : 10.19581/j.cnki.ciejournal.2014.11.005 